the head continues, and she complains also of a constant feeling of formication, especially in the skin about the chin. There is ptosis of the left eyelid, dilatation of the left pupil, some amount of external strabismus, and the movements of the eye are exceedingly limited. There is marked protrusion of the left eyeball, which seems scarcely to be overcome by light pressure upon it, but at the same time the pressure causes no pain. There is aome deafness of the left ear, which, as far as I can ascertain from an examination by the tuning fork, seems to be of central origin. The patient, however, is unintelligent and inattentive, and I do not feel that my results by this test are conclusive. There is some redness and tenderness of the lining of the external auditory meatus, with a tendency to the formation of a large amount of cerumen, but the tympanum is tolerably healthy, and the meatus was well cleared previous to the examination. The tongue on protrusion deviates very slightly but constantly to the left. There is a suspicion of some amount of paralysis of the right side of the face. Smell and taste are normal. The sight of the left eye is defective, the outline of objects being indistinct ; there is, however, no hemianopsia or other contraction of the field of vision. There is slight evidence of commencing optic neuritis at one point in the right eye. The pupils contract only feebly to light.

During the patient's stay in the infirmary no important changes took place in her symptoms. Antisyphilitic remedies among others were tried, but without producing any important result. A careful consideration of the history and symptoms of the case has led me to the opinion that in all probability there is a tumour at the base of the brain, corresponding with the middle fossa of the skull, its influence by meningitis or otherwise extending beyond this limit so as to affect the auditory and hypoglossal nerves.

The chief points to which I desire to call attention in reference to the neuralgic paroxysms are-1st, that three divisions of the fifth nerve are implicated; and 2 nd, that although during the paroxysms there is general hyperresthesia of the surface, and that considerable pain is caused by pressure at certain points over the nerves, yet that these conditions are entirely absent in the intervals between the attacks. These two facts seem to me to point very strongly to the central origin of the disease. The opposite conditions exist in cases associated with peripheral causes. There seems to be tolerably complete paralysis of the motor-ocul nerve; and notwithstanding the fact that the exophthalmos cannot be overcome by light pressure, it may still perhaps result from a paralysed condition of all the ocular muscles. The deafness that exists, although slight, probably depends upon some direct implication of the auditory nerve. It is then tolerably clear that this lesion, whatever it may be, implicates the third, fifth, and ninth nerves; and there is considerable ground for thinking that the portio mollis of the left side and the portio dura of the right side are also involved. The base of the brain is pretty certainly indicated as the locality of the mischief, and there are no symptoms to lead one to suppose that the part of the brain or any of the nerves lying in the anterior fossa are in any way concerned, and the nerves connected with that portion of the brain which lies in the middle fossa of the skull are those whose functions are chiefly disturbed. This may not, however, represent its exact limitation, as we find some evidence even of paralysis of the ninth nerve. The steady, persistent, and progressive character of the symptoms leads one to the opinion that they are due to a tumour (occupying the middle fossa) rather than to a basilar meningitis, although their somewhat irregular extension may arise from the coexistence of this latter condition.

Sheffield.

\section{ON A CASE OF THROMBOSIS.}

By MILNER MOORE, M.D., M.R.C.S.,

SURGEON TO THE COVENTRY AND WARWICKSHIRE HOSPITAL.

AT a time when a case of thrombosis has been recently brought for discussion before the Clinical Society, it may be interesting to place on record a somewhat similar case, more especially as medical literature is not particularly fruitful in the description of accidents of this sort.

Mr. $\mathrm{H}-$, forty-six years of age, had always been a robust and healthy man, but, owing to an accident during his youth, he had partial anchylosis of the right knee in a semiflexed position. While out walking, about two miles frum home, on Dec. $6 \mathrm{th}, 1883$, he slipped in the snow and fell, breaking the right femur at its lower third. Assistance was soon obtained, and he was kept warm with shawls and wraps, but fully two hours elapsed before he was conveyed home under Dr. Thompson's supervision. My assistance was then sought, and, seeing the difficulty of setting the fracture in the usual way, owing to the anchylosed knee, $I$ applied bandages of plaster-of-Paris, while Dr. Thompson kept up extension until the plaster had set. The limb was then put at rest upon a McIntyre's splint. All appeared to progress satisfactorily until Dec. 23rd, when I received a summons, and found that pneumonia of the right lower and middle lobes had set in. This ran its course without complications, with the exception of rather obstinate constipation, and all appeared to be going on well until January 14th, when pain occurred with some severity on the inner surface of the left thigh, which rapidly became enormously swollen and oedematous. Within three days the right extremity above and below the plaster case became cedematous also, and on both sides, as high as the umbilicus, the skin was boggy, and retained marks of the finger-nails for several minutes. With the aid of hot fomentations and bandages, combined with the administration of purgatives and diuretics, the cedema sub. sided to a certain extent, and it was considered advisable to remove the plaster-case, when the fracture was found to be fairly united. The case was reapplied for the purpose of support, and the patient was advised to move about with the aid of crutches in the early days of February. Mr. H- then went to Bournemouth, but while there he did not improve, and was so unable to use his legs (the leit especially) in walking, that I advised him on his return journey to call and see Dr. Broadbent. This he did; and Dr. Broadbent's opinion is that a clot still exists in the inferior vena cava. Since his return home the patient has much improved under the application of gentle shampooing and rest in the recumbent position, with occasional gentle out-door exercise when the weather permits. The sequence of events-simple fracture of the femur, pneumonia, and thrombosis-renders this a very interesting and instructive case ; and what makes it still more interesting, is the fact that the patient is now rapidly recovering.

Coventry.

\section{A. 然litrror}

\section{HOSPITAL PRACTICE, BRITISH AND FOREIGN.}

Nullaautem estalia pro certo noscendivia, nisi quamplurimas et morborum et dissectionum historias, tum aliorum tum proprias collectas habere, et Inter se comparare.-Morgatert De Sed. et Oaus. Morb., lib. ir. Proomium.

\section{ST. THOMAS'S HOSPITAL.}

BULLET WOUND OF BRAIN FROM THE LEFT TEMPLE, FOLLOWED BY RIGHT HEMIPLEGIA, OPTIC NEURITIS, AND EPILEPSY ; EXPLORATION AND REMOVAL OF FRAG: MENTS OF THE BULLET AND DEPRESSED SPICULA OF BONE ; RECOVERY.

(Under the care of Mr. SyDNEY JoNES.)

For the following notes we are indebted to Mr. W. H, Battle, surgical registrar.

J. G-, aged twenty-one, a clerk, was admitted on Dec. 11th, 1882, and left March 8th, 1883. He was re. admitted Dec. 19th, 1883, and left Feb. 2nd, 1884.

On December 10th, 1882, at 2 A.M., the patient was found in an unconscious condition, having shot himself in the forehead. When found blood and brain-substance were escaping from the wound. He had two attacks of convulsions : one at $8 \mathrm{~A}$.M. and another at $20^{\text {'clock }}$ the following morning.

When admitted on the 11th he was almost unconscions, breathing rapidly; there was a small bullet wound on the left temple, filled with clot, the integuments around being puffy. The wound was situated two inches and a half above the left brow and an inch external to the middle line. The patient groaned frequently, as if in pain. When told to do so he moved his left leg and arm, but had little command over the right arm and leg, which were, however, moved frequently in a spasmodic manner; the sensation was nearly, if not quite, abolished on the right side, but was good on the left. He could not protrude his tongue. The papils were 